\title{
Safety and Efficacy of Neostigmine Against Residual Neuromuscular Blockade in Pediatric Patients During Recovery From General Anesthesia: A Retrospective Cohort Study
}

\author{
Hongyang Chen \\ West China Hospital of Sichuan University \\ Lei Yang \\ West China Hospital of Sichuan University \\ Zining Wang \\ West China Medical Center of Sichuan University \\ Di Yang \\ Sichuan Academy of Medical Sciences \& Sichuan Provincial People's Hospital \\ Weiyi Zhang \\ West China Hospital of Sichuan University \\ Tao Zhu ( $\nabla$ xwtao.zhu@gmail.com ) \\ West China Hospital of Sichuan University
}

\section{Research Article}

Keywords: Muscle relaxation antagonism, Neostigmine, Pediatric anesthesia

Posted Date: November 15th, 2021

DOI: https://doi.org/10.21203/rs.3.rs-967875/v1

License: (c) (i) This work is licensed under a Creative Commons Attribution 4.0 International License.

Read Full License 


\section{Abstract}

Introduction: with the wide application of muscle relaxants in clinic, the anesthesiologists pay more and more attention to the residual neuromuscular block. While the pediatric patients have poor tolerance to hypoxia, compared to adult patients, the residual neuromuscular block do more harm to them in recovery period of anesthesia, such as respiratory failure, hypoxia, asphyxia and even death. In order to reduce the risk of the residual neuromuscular block complications, we design the following regression cohort study to conform the safety and effectiveness of routine use of neostigmine after operation.

Methods: This study was a retrospective cohort study (ChiCTR1900028048), approved by the ethics committee of West China Hospital, Sichuan University. We reviewed pediatric patients who received surgical treatment in West China Hospital, Sichuan University from January 1, 2018 to September 30, 2019.The exposure factor was the use of neostigmine during the period of anesthesia recovery. Inclusion criteria: the pediatric surgery department patients who underwent general anesthesia in West China Hospital, Sichuan University. Exclusion criteria: cases without medical electronic records; Cases with missing outcome data; No muscle relaxants were used during general anesthesia. The outcomes included: lowest pulse oxygen saturation after endotracheal extubation; incidence of hypoxemia after endotracheal extubation; in-hospital mortality; length of hospital stay; medical expenses. IBM SPSS Statistics 23.0 software was used for statistical analysis.1:1 propensity score matching was used to eliminate the influence of confounding factors. For continuous variables, student $t$ test was used . For categorical variables, the chi-square test was used. The results were considered statistically significant, if $p$ value $<0.05$. Subgroup analysis was performed according to the age ( $<2$ years / 3-5 years or $>6$ years) and the dose of neostigmine (low dose group $<=0.02 \mathrm{mg} / \mathrm{kg}$ or high dose group $>0.02 \mathrm{mg} / \mathrm{kg}$ ).

Results: A total of 4358 pediatric patients were included. After 1:1 propensity score matching, 1820 pediatric patients were included for statistical analysis. In-hospital mortality (1/910 vs 0/910, $p=0.32)$, lowest pulse oxygen saturation after endotracheal extubation ( $98.90 \pm 3.05$ vs $98.78 \pm 3.48, p=0.43)$, incidence of hypoxemia after endotracheal extubation $(23 / 910$ vs $21 / 910, p=0.76)$, length of hospital stay $(5.66 \pm 6.11$ vs $5.88 \pm 6.59, p=0.46)$, and medical expenses $(17967.04 \pm 21325.86$ vs $17406.96 \pm 18358.17, p=0.55)$ showed no significantly statistical differences between the pediatric patients with or without neostigmine application to reverse the neuromuscular blockade during anesthesia recovery. Subgroup analysis found no significant associations between the outcomes and age of the patients or the dose of neostigmine.

Conclusion: For pediatric patients, neostigmine application to reverse the neuromuscular blockade was not significantly associated with in hospital mortality, lowest pulse oxygen saturation after endotracheal extubation, incidence of hypoxemia after endotracheal extubation, medical expenses, or length of hospital stay. However, as some confounding factors cannot be eliminated in this retrospective study, the results of this study are needed to be confirmed by future prospective studies.

Trial registration: Medical records based study for the recovery effect of antagonitst of muscle relaxant in pediatric patients, ChiCTR1900028048, Registered 8 September 2019, 


\section{Introduction}

As the application of muscle relaxants can improve the operation and anesthesia conditions of patients under general anesthesia, which is conducive to the operation and the establishment of airway and the maintenance of mechanical ventilation, muscle relaxant is one of the most commonly used general anesthetics ${ }^{[1]}$. However, with the mass use of muscle relaxant, the residual neuromuscular blockade was widely found in clinical work ${ }^{[2-6]}$. Among this effect, the incidence in the post anesthesia care unit(PACU) in children was $26.9 \%$, and in operation room was as high as $48.2 \%{ }^{[7]}$. The residual neuromuscular blockade may lead respiratory related complications to patients in anesthesia recovery stage, such as, decreased breathing, hypoxia, asphyxia and may lead to serious adverse events, even death ${ }^{[4,6]}$. Because the pediatric patients are inherently poorly tolerant to hypoxia, compared to the adult patients, the residual paralysis is more dangerous to pediatric patients ${ }^{[1]}$. So, in clinical work, measures are warranted to reduce complications in pediatric patients with residual paralysis.

Studies have shown that the application of neuromuscular monitoring can reduce the incidence of residual neuromuscular blockade ${ }^{[8]}$. Therefore, various clinical guidelines and expert consensus refer to neuromuscular monitoring in patients with muscle relaxants ${ }^{[9,10]}$. However, data from the foreign country shows that, even in European and American developed countries, muscle relaxation monitor has not been fully popularized. A study shows that, in American and European, the proportion of anesthesiologists, who has the condition to use the muscle relaxation monitor, was $22.7 \%$ and $70.2 \%$ respectively ${ }^{[11]}$. In France, only $52 \%$ of anesthesiologists will make a routine of neuromuscular monitoring ${ }^{[12]}$. A latest study in Denmark shows that, only $68 \%$ of nurse anesthesiologists and $47 \%$ of anesthesiologists will use the muscle relaxation monitor for routine ${ }^{[13]}$. Compared to the anesthesiologists who use the muscle relaxation monitor for routine, we should pay more attention to the proportion of anesthesiologists who never use the muscle relaxation monitor. In Australia and New Zealand, 10\% of anesthesiologists never use the muscle relaxation monitor ${ }^{[14]}$. In Greece, $13.7 \%$ of respondents said that they never use the muscle relaxation monitor ${ }^{[15]}$. The number in England is $62 \%{ }^{[16]}$, even in Mexico, the number is $98 \%[17]$. Therefore, without the help of muscle relaxation monitor, anesthesiologists always judge whether there is residual muscle relaxation in patients and need to use muscle relaxant antagonists according to their own clinical experience. A study of Italian anesthesiologists shows that $73 \%$ of them judge the muscle relaxation disappeared by clinical manifestations, including looking up for more than 5 seconds, tongue out and eyes open ${ }^{[18]}$. However, the study found that, though the patients appear those clinical manifestations, the ratio of train of four stimulation may less than 0.9 and can't completely rule out the residual neuromuscular blockade ${ }^{[10,19]}$. There is no related literature was published on the prevalence of muscle relaxation monitoring in China. Because the prevalence of muscle relaxation monitoring involves the investment of medical education and medical funds, we need a long time to achieve the desired 
results. As the muscle relaxation monitoring is not popular as other countries, we need to find alternatives to avoid or reduce the occurrence of complications of the residual muscle relaxation.

According to the literature, routine use of muscle relaxant antagonists is conducive to reduce the incidence of residual neuromuscular blockade instead of using muscle relaxation monitor ${ }^{[19-21]}$. There are two kinds of muscle relaxants commonly used in clinic at present, the representative drugs are neostigmine and sugammadex sodium.

Neostigmine as a reversible cholinesterase inhibitor, increases acetylcholine at the neuromuscular junction mainly by inhibiting its breakdown by cholinesterase, increasing competition with nondepolarizing muscle relaxants, leading muscle relaxant antagonism. The partition and elimination half-life period of neostigmine are 3.4 minutes and 77 minutes respectively ${ }^{[22]}$. While in pediatric patients, the elimination half-life period is shorter than adult patient ${ }^{[23]}$. Because neostigmine is competitively inhibitory to nondepolarizing muscle relaxants, with the increasing of dose, the inhibitory will increase and reach the maximum effective dose namely ceiling effect. Currently, it is believed that the maximum effective dose of neostigmine is $0.06-0.08 \mathrm{mg} / \mathrm{kg}$. In combination with atropine, the recommended dose to pediatric patients for reversal of nondepolarizing muscle relaxants is $0.02-0.06 \mathrm{mg} / \mathrm{kg}^{[22]}$. Compared to pediatric or adolescent patients, neostigmine takes less time to reverse the residual neuromuscular blockade $^{[24]}$. Because giving neostigmine will increase the acetylcholine and increase the stimulation of nicotinic and muscarinic receptors, the adverse effects of neostigmine, such as bradycardia, salivation, nausea and vomiting, are closely related to overstimulation of cholinergic nerves ${ }^{[25,26]}$. Cardiac arrhythmias and bronchospasm were also reported in severe cases ${ }^{[27]}$.

Sugammadex sodium is derived from natural cyclodextrins. In pharmacology, cyclodextrins are widely used to increase the solubility of lipophilic compounds in water ${ }^{[28]}$. Therefore, early sugammadex sodium was developed for use as a rocuronium solvent. Sugammadex sodium contain eight separate hydroxyl chains, which were used to encapsulate rocuronium. Certainly, sugammadex sodium can also be combined with vecuronium and pancuronium, but with lower affinity than rocuronium ${ }^{[29]}$. Because sugammadex sodium combine with rocuronium in vascular, it effectively lowers the free rocuronium concentrations in plasma, making the concentration differences and letting more rocuronium diffuse from the neuromuscular junction to the plasma. At the same time, sugammadex sodium will diffuse from the plasma to outside and combine any rocuronium it encounters ${ }^{[30]}$. Sugammadex sodium is all renally metabolized, its elimination half-life period is about 100 150 minutes. The sugammadex sodium dose correlated with the degree of block produced by rocuronium ${ }^{[10,31]}$. Theoretically, one molecule of sugammadex sodium is able to bind one molecule of rocuronium. To ensure rapid and efficient reversal of neuromuscular blockade of rocuronium, sugammadex sodium should be used in relative excess ${ }^{[30]}$. In contrast to neostigmine, sugammadex sodium does not inhibit the action of acetylcholinesterase, so, it doesn't lead to cholinergic nervous system related complications in clinical use ${ }^{[32]}$. It is more possible to lead to serious adverse reactions, such as, allergies, arrhythmias, and coagulopathy. There was retrospective study found that, the incidence of allergies is only $0.039 \%{ }^{[33]}$. But in case control study of 
pediatric general anesthesia patients, it didn't find the allergy in operation has relation with sugammadex sodium $^{[34]}$. Besides, partial literature found that sugammadex sodium can relieve the allergy caused by rocuronium ${ }^{[35-38]}$. Although all the current published clinical studies show that sugammadex sodium in pediatric patients, including neonates, infants, preschool children, school aged children as well as adolescent patients, has the same efficacy and safety as adult patient ${ }^{[39-41]}$. Limited data are currently available and sugammadex sodium is expensive, it is not referred to pediatric patients. So, the most common muscle relaxant antagonist in clinical is still neostigmine. But inappropriate using large dose of neostigmine may lead to reverse effect, making neuromuscular block again ${ }^{[42]}$. It has also been reported in the literature that the use of neostigmine may increase the risk of airway collapse and lead to muscle

weakness $^{[43]}$. Besides, neostigmine has some correlation with postoperative respiratory complications ${ }^{[44]}$. But recent literature ${ }^{[5]}$ found that there is no muscle weakness, when give neostigmine in adult patients whose muscle tone had recovered. So, without muscle relaxation monitor, whether routine use of neostigmine is safe and effective in antagonizing the residual neuromuscular block in children needs further study.

In conclusion, with the wide application of muscle relaxants in clinic, the anesthesiologists pay more and more attention to the residual neuromuscular block. While the pediatric patients have poor tolerance to hypoxia, compared to adult patients, the residual neuromuscular block do more harm to them in recovery period of anesthesia, such as respiratory failure, hypoxia, asphyxia and even death. In order to reduce the risk of the residual neuromuscular block complications, we design the following regression cohort study to conform the safety and effectiveness of routine use of neostigmine after operation.

\section{Methods}

This study was approved by the ethics committee of West China Hospital of Sichuan University (Grant No.2019(874)). It registered in China clinical trial registration network before the implementation of the study, the registration number is ChiCTR1900028048.

This is a retrospective cohort study. West China Hospital of Sichuan University is the hospital to carry out this study. The hospital is a research-oriented hospital in the western region of China, with an annual operation volume of over 100000 . The patients admitted are not only from Sichuan Province, but also from neighboring provinces and cities, including Guizhou, Yunnan, Tibet, Qinghai and other provinces and cities. Therefore, the number of children with surgery in our hospital is large and covers a wide area, and the data obtained are representative. Since the new surgical anesthesia information system has been launched in the medical center since 2018 , we only reviewed and analyzed the pediatric surgical patients who underwent surgery in the center from January 1, 2018 to September 30, 2019. The exposure factor is the antagonism of neostigmine on neuromuscular blockade during the recovery period of general anesthesia. Therefore, in this study, the exposed group is the children who used neostigmine during the recovery period of general anesthesia, and the non-exposed group is the children who did not use neostigmine during the recovery period of general anesthesia. All data are as of discharge. 
The inclusion criteria of this study are any patients who underwent general anesthesia in pediatric surgery department of West China Hospital of Sichuan University. Exclusion criteria: cases without electronic case system to record the use of neostigmine: for example, the children were transferred to the PACU for extubation or admitted to the pediatric ICU after operation (the operation anesthesia system of the anesthesia operation center of West China Hospital of Sichuan University did not cover the PACU and pediatric ICU); The cases with missing records of outcome indicators; No muscle relaxants were used during the operation.

The evaluation indexes of this study include:

1. The lowest oxygen saturation after extubation: the pulse oxygen saturation recorded by the surgical anesthesia system shall prevail.

2. Incidence of hypoxemia after extubation: when the lowest pulse oxygen saturation after extubation is lower than $90 \%$, the patient is considered to have hypoxemia after extubation. If the lowest pulse oxygen saturation after extubation is higher than $90 \%$, it is considered that there is no hypoxemia after extubation.

3. Mortality during hospitalization: screening according to the way of leaving hospital. If the way of leaving hospital is death, it is considered that the child died during hospitalization. If the way of children leaving hospital is doctor's order, with or without doctor's order transfer or other, it is considered that there is no death during hospitalization.

4. Days of hospitalization: the data extracted by the electronic case system of the child shall prevail. The number of days in hospital includes all the time of the child in hospital, that is, if the child changes to another department during the hospitalization, the time of treatment in other departments is also calculated.

5. Total medical expenses during hospitalization: according to the data extracted from the electronic case system for children. Medical expenses include operation expenses, anesthesia expenses, nursing expenses, consultation expenses, bed expenses, etc.

The data of this study are from the operation anesthesia information system of the anesthesia operation center of West China Hospital of Sichuan University and the electronic case system (hospital information system, HIS) of West China Hospital of Sichuan University. Among them, American society of anesthesiologists (ASA) grade, gender, age, weight, airway management during general anesthesia (endotracheal intubation / laryngeal mask airway / others), anesthesia time (minutes), operation time (minutes), intraoperative infusion volume (ML), lowest oxygen saturation after extubation, incidence of hypoxemia after extubation, use of neostigmine, use of muscle relaxants, the information of opioid use and intraoperative blood transfusion came from the operation anesthesia information system. The length of stay, hospitalization related expenses and death information during hospitalization all came from the hospital HIS system. We used the VLOOKUP function in Microsoft Excel 2016 software to associate the two data sets according to the name, hospitalization number and operation date of the child, and combine them into a data set for analysis. Because some children in the center will take tube into PACU 
and pull out tube, but the anesthesia information system has not been installed in the recovery room of the center, it is impossible to obtain the situation of neostigmine given during the recovery period of general anesthesia and oxygen saturation during the withdrawal period of this part of children. Therefore, we plan to exclude this part of the children. If there is no record of tracheal tube extubation in the operation anesthesia information system, we assume that the child did not pull out the tube in the operation room, so we excluded this part of the children. In the data set after the merger, we will sort out the relevant case information data of children and we will transform and calculate the extracted information in batches to meet the needs of statistical analysis. First, use Microsoft Excel 2016 replacement mode or if function to replace the extracted text format information with digital information, such as gender, ASA grade, etc. Secondly, the calculation model in Microsoft Excel 2016 was used to calculate the dosage of neostigmine per kilogram of body weight for each included child. Finally, we use Microsoft Excel 2016 COUNTIF function to sort out the number of users of various muscle relaxants and opioids.

We plan to use IBM SPSS Statistics 23.0 software for statistical analysis of the results. For continuous variables, we plan to use $T$ test. For categorical variables, we plan to use chi square test. When $p<0.05$, we think the results have statistical difference. In addition, since this study is a retrospective cohort study, there may be more confounding factors in the included data, so we plan to use propensity score matching method to eliminate the impact of confounding factors on the results. First, we plan to compare the baseline information of the included children, including gender, age, weight, ASA grade, airway management during general anesthesia (endotracheal intubation / laryngeal mask airway / other), anesthesia time (minutes), operation time (minutes), intraoperative infusion volume (ML), use of muscle relaxants (drug types), the use of opioids (type of drug used) and intraoperative blood transfusion. If there are significant differences between the baseline, we will match the propensity scores according to the factors that caused the differences. We plan to use IBM SPSS Statistics 23.0 software to match the 1:1 propensity score between the exposed group and the non-exposed group. In the IBM SPSS statistics 23.0 software, click data in turn, match the propensity score, set whether neostigmine is used after anesthesia recovery period as the group indicator, and ASA grade, gender, age, weight, anesthesia time, operation time, intraoperative infusion volume, airway device, intraoperative blood transfusion, muscle relaxant use, opioid use as the predictive variables, The matching tolerance is set to 0.02 . The matching results are sorted into a new data set for further statistical analysis.

In addition, we plan to analyze the results according to the age of the children $(<2$ years old / 3-5 years old / > 6 years old) and the dosage of neostigmine (low dose group $<=0.02 \mathrm{mg} / \mathrm{kg} /$ high dose group $>$ $0.02 \mathrm{mg} / \mathrm{kg}$ ).

\section{Result}

In this study, 11823 child records were derived from the electronic case system, 20610 child records were derived from the surgical anesthesia system, and a total of 9357 child records were derived after duplicate removal. 4223 cases of extubation in PACU were excluded, 417 cases of missing medical 
expenses were excluded, 359 cases of children without using muscle relaxants were excluded, and the data of the remaining 4358 cases were analyzed (see Figure. 1 for details).

When comparing the basic information of the children included, there were significant statistical differences between the exposed group and the non-exposed group in terms of gender, age, weight, ASA grade, airway management device, anesthesia time, operation time, infusion volume, whether blood transfusion during operation, use of muscle relaxant and opioid drugs (see table 1 for details). Therefore, we matched the inclusion data with a 1:1 propensity score. After matching, there was no significant difference in gender, age, weight, ASA grade, airway management device, anesthesia time, operation time, infusion volume, blood transfusion, muscular relaxant use and opioid drug use (see Table 2 for details). Finally, we included 1820 children data for the next statistical analysis.

Table 1. basic information of patients before matching tendency score $(\mathrm{N}=4358)$

\section{a. Categorical variable data}




\begin{tabular}{|c|c|c|c|}
\hline & $\begin{array}{l}\text { Exposed group } \\
(n=3420)(\%)\end{array}$ & $\begin{array}{l}\text { Non-exposed } \\
\text { group }(n=938)(\%)\end{array}$ & $\begin{array}{l}p \\
\text { value }\end{array}$ \\
\hline Gender & & & 0.02 \\
\hline Male & 2293(67) & $589(63)$ & \\
\hline Female & 1127(33) & $349(37)$ & \\
\hline ASA grade & & & 0.01 \\
\hline 1 & $548(16)$ & 120(13) & \\
\hline 2 & $2610(76)$ & 735(78) & \\
\hline 3 & 257(8) & $78(8)$ & \\
\hline 4 & $5(0)$ & $5(0)$ & \\
\hline 5 & 0 & 0 & \\
\hline Airway device & & & 0.00 \\
\hline Tracheal intubation & $1669(49)$ & $532(57)$ & \\
\hline Laryngeal mask & 1751(51) & 405(43) & \\
\hline Mask & 0 & $1(0)$ & \\
\hline $\begin{array}{l}\text { Intraoperative blood } \\
\text { transfusion }\end{array}$ & & & 0.00 \\
\hline Yes & $60(2)$ & 42(4) & \\
\hline No & $3360(98)$ & $896(96)$ & \\
\hline Use of muscle relaxants & & & 0.00 \\
\hline CIS atracurin alone & 3385(99) & $912(97)$ & \\
\hline Rocuronium alone & $10(0)$ & $7(1)$ & \\
\hline Vecuronium alone & $12(0)$ & $11(1)$ & \\
\hline Combine of two relaxants & $13(0)$ & $8(1)$ & \\
\hline Opioids & & & 0.00 \\
\hline Sufentanil alone & $468(14)$ & 181(19) & \\
\hline Fentanyl alone & $2080(61)$ & $547(58)$ & \\
\hline $\begin{array}{l}\text { Combine Fentanyl and } \\
\text { Sufentanil }\end{array}$ & $863(25)$ & $202(22)$ & \\
\hline Not using opioids & $9(0)$ & $8(1)$ & \\
\hline
\end{tabular}


b $\square$ Continuous variable data

\begin{tabular}{|llll|}
\hline & $\begin{array}{l}\text { Exposed group (Mean } \pm \\
\text { standard deviation) }(\mathrm{n}=\mathbf{3 4 2 0})\end{array}$ & $\begin{array}{l}\text { Non-exposed group (Mean } \pm \\
\text { standard deviation) }\end{array}(\mathrm{n=938)}$ & $\begin{array}{l}\mathrm{p} \\
\text { value }\end{array}$ \\
\hline Age(year) & $4.88 \pm 3.39$ & $5.46 \pm 3.49$ & 0.00 \\
\hline Weight(kg) & $17.72 \pm 10.22$ & $19.97 \pm 11.36$ & 0.00 \\
\hline $\begin{array}{l}\text { Anesthesia } \\
\text { duration (minutes) }\end{array}$ & $99.81 \pm 56.37$ & & 0.00 \\
\hline $\begin{array}{l}\text { Operative } \\
\text { time (minutes) }\end{array}$ & $53.66 \pm 44.93$ & $116.27 \pm 72.75$ & \\
\hline $\begin{array}{l}\text { Intraoperative } \\
\text { infusion } \\
\text { volume (ML) }\end{array}$ & $352.58 \pm 268.65$ & $66.11 \pm 59.51$ & 0.00 \\
\hline
\end{tabular}

Table 2. Patient base information after propensity score matching ( $N=1820)$

a. Categorical variable data 


\begin{tabular}{|c|c|c|c|}
\hline & $\begin{array}{l}\text { Exposed group } \\
(n=910)(\%)\end{array}$ & $\begin{array}{l}\text { Non-exposed } \\
\text { group }(n=910)(\%)\end{array}$ & $\begin{array}{l}p \\
\text { value }\end{array}$ \\
\hline Gender & & & 0.41 \\
\hline Male & $589(65)$ & $572(63)$ & \\
\hline Female & $321(35)$ & $338(37)$ & \\
\hline ASA grade & & & 0.47 \\
\hline 1 & 134(15) & 119(13) & \\
\hline 2 & 697(77) & 714(78) & \\
\hline 3 & $77(8)$ & $72(8)$ & \\
\hline 4 & $2(0)$ & $5(1)$ & \\
\hline 5 & 0 & 0 & \\
\hline Airway device & & & 0.23 \\
\hline Tracheal intubation & 490(54) & $519(57)$ & \\
\hline Laryngeal mask & $420(46)$ & $390(43)$ & \\
\hline Mask & 0 & $1(0)$ & \\
\hline $\begin{array}{l}\text { Intraoperative blood } \\
\text { transfusion }\end{array}$ & & & 0.44 \\
\hline Yes & 28(3) & $34(4)$ & \\
\hline No & $882(97)$ & $876(96)$ & \\
\hline Use of muscle relaxants & & & 0.81 \\
\hline CIS atracurin alone & 891(97) & $886(97)$ & \\
\hline Rocuronium alone & $5(1)$ & $7(1)$ & \\
\hline Vecuronium alone & $6(1)$ & $9(1)$ & \\
\hline Combine of two relaxants & $8(1)$ & $8(1)$ & \\
\hline Opioids & & & 0.65 \\
\hline Sufentanil alone & 167(18) & 170(19) & \\
\hline Fentanyl alone & $518(57)$ & $530(58)$ & \\
\hline $\begin{array}{l}\text { Combine Fentanyl and } \\
\text { Sufentanil }\end{array}$ & $220(24)$ & 202(22) & \\
\hline Not using opioids & $5(1)$ & $8(1)$ & \\
\hline
\end{tabular}


b[Continuous variable data

\begin{tabular}{|llll|}
\hline & $\begin{array}{l}\text { Exposed group (Mean } \pm \\
\text { standard deviation) }(\mathrm{n}=910)\end{array}$ & $\begin{array}{l}\text { Non-exposed group (Mean } \pm \\
\text { standard deviation) }(\mathrm{n}=910)\end{array}$ & $\begin{array}{l}\mathrm{p} \\
\text { value }\end{array}$ \\
\hline Age(year) & $5.27 \pm 3.65$ & $5.42 \pm 3.50$ & 0.38 \\
\hline Weight(kg) & $19.32 \pm 12.02$ & & 0.34 \\
\hline $\begin{array}{l}\text { Anesthesia } \\
\text { duration (minutes) }\end{array}$ & $107.90 \pm 63.65$ & $19.85 \pm 11.29$ & 0.05 \\
\hline $\begin{array}{l}\text { Operative } \\
\text { time (minutes) }\end{array}$ & $59.19 \pm 49.36$ & $113.82 \pm 65.50$ & \\
\hline $\begin{array}{l}\text { Intraoperative } \\
\text { infusion } \\
\text { volume (ML) }\end{array}$ & $379.48 \pm 286.02$ & $63.52 \pm 52.43$ & 0.07 \\
\hline
\end{tabular}

The results showed that there was 1 case of in-hospital death in the anesthesia recovery exposed group, while there was no death in the non-exposed group. There is no significant difference between the two groups $(p=0.32)$. After extubation, the mean lowest oxygen saturation in the exposed group is $98.90 \%$, while the non-exposed group is $98.78 \%$, there is no significant difference between the two groups $(p=0.43)$. The incidence of hypoxemia after extubation in the exposed group is $2.53 \%(23 / 910)$, while the non-exposed group is $2.31 \%(21 / 910)$, there is no significant difference between the two groups $(p=0.76)$. The average length of stay in hospital in the exposed group are 5.66 , while the nonexposed group are 5.88 , there is no significant difference between the two groups $(p=0.46)$. The average hospitalization expenses of the exposed group are 17967.04 yuan, while the non-exposed group are 17406.96 yuan, there is no significant difference between the two groups $(p=0.55)$ (see Table 3 for details).

Table 3. Outcome indicators after propensity score matching( $\mathrm{N}=1820)$

We performed a subgroup analysis based on age (see Table 3 for details).

In the infant group ( $<=2$ years old), the mean lowest oxygen saturation after extubation in the exposed group is $98.82 \%$, while the non-exposed group is $98.33 \%$, there is no significant difference between the two groups $(\mathrm{p}=0.28)$. The incidence of hypoxemia after extubation in the exposed group is $3.42 \%(10 / 292)$, while the non-exposed group is $2.66 \%$ (7/263), there is no significant difference between the two 
Exposed group (Mean \pm standard deviation) $(n=910)$
Non-exposed group (Mean \pm standard deviation) $(n=910)$ p value

$1 / 909$

$0 / 910$

0.32 occurred)

\section{The}

\section{lowest oxygen}

saturation (\%)

$<=2$ years old

3-5 years old

$>=6$ years old

\section{Frequency of hypoxemia (occurred / not occurred)}

$<=2$ years old

3-5 years old

$>=6$ years old

\section{Length of stay(day)}

$<=2$ years old

3-5 years old

$>=6$ years old

\section{Hospitalization expenses (yuan)}

$<=2$ years old

3-5 years old

$>=6$ years old
$98.90 \pm 3.05$

$98.78 \pm 3.48$

0.43
$98.82 \pm 3.58$

$98.97 \pm 3.11$

$98.95 \pm 2.58$

$23 / 887$

$10 / 282$

$6 / 221$

$7 / 384$

$5.66 \pm 6.11$

$4.37 \pm 4.96$

$5.59 \pm 5.54$

$6.66 \pm 6.98$

$17967.04 \pm 21325.86$

$13896.37 \pm 12609.51$

$17670.34 \pm 16973.71$

$21179.28 \pm 27415.71$
$98.33 \pm 6.83$

0.28

$98.41 \pm 7.60$

0.30

$98.60 \pm 5.92$

0.29

$21 / 889$

0.76

$7 / 256$

0.60

$5 / 227$

0.73

9/406

0.70

groups $(p=0.60)$. The average length of hospital stay in the exposed group are 4.37 days, while the nonexposed group are 4.65 days, there is no significant difference between the two groups $(p=0.46)$. The average hospitalization expenses of the exposed group are 13896.37 yuan, while the non-exposed group are 15250.31 yuan, there is no significant difference between the two groups $(p=0.18)$. 
In the preschool group (3-5 years old), the mean lowest oxygen saturation after extubation in the exposed group is $98.97 \%$, while the non-exposed group is $98.41 \%$, there is no significant difference between the two groups $(\mathrm{p}=0.30)$. The incidence of hypoxemia after extubation in the exposed group is $2.64 \%(6 / 227)$, while the non-exposed group is $2.16 \%$ (5/232), there is no significant difference between the two groups $(p=0.73)$. The average length of hospital stay in the exposed group are 5.59 days, while the nonexposed group are 6.08 days, there is no significant difference between the two groups $(p=0.37)$. The average hospitalization expenses of the exposed group are 17670.34 yuan, while the non-exposed group are 18591.82 yuan, there is no significant difference between the two groups $(p=0.64)$.

In the school aged children group (>6 years old), the mean lowest oxygen saturation after extubation in the exposed group is $98.95 \%$, while the non-exposed group is $98.60 \%$, there is no significant difference between the two groups $(\mathrm{p}=0.29)$. The incidence of hypoxemia after extubation in the exposed group is $1.79 \%(7 / 391)$, while the non-exposed group is $2.17 \%(9 / 415)$, there is no significant difference between the two groups $(p=0.70)$. The average length of hospital stay in the exposed group are 6.66 days, while the non-exposed group are 6.50 days, there is no significant difference between the two groups $(p=0.76)$. The average hospitalization expenses of the exposed group are 21179.28 yuan, while the non-exposed group are 17986.47 yuan, there is no significant difference between the two groups $(p=0.05)$.

In addition, we also performed subgroup analysis based on the dose of neostigmine (see table 4 for details):

In the exposed group of 910 children, we divided the children into the low dose ( $<0.02 \mathrm{mg} / \mathrm{kg})$ exposed group and the high dose $(>0.02 \mathrm{mg} / \mathrm{kg}$ ) exposed group. There are 829 cases in the low-dose exposed group and 78 cases in the high-dose exposed group. In the low-dose exposed group, there was one case of death in hospital. In the high-dose exposed group, there was no death in hospital, there is no significant difference between the two groups $(p=0.76)$. The mean lowest oxygen saturation in the low dose exposed group is $98.92 \%$, while the high-dose exposed group is $98.83 \%$, there is no significant difference between the two groups $(p=0.81)$. The incidence of hypoxemia in the low dose exposed group is $2.41 \%(20 / 829)$, while the high-dose exposed group is $3.85 \%(3 / 78)$, there is no significant difference between the two groups $(p=0.44)$. The average length of hospital stays in the low dose exposed group are 5.67 days, while the high-dose exposed group are 5.51 days, there is no significant difference between the two groups $(p=0.83)$. The average hospitalization expenses of the low dose exposed group are 17957.52 yuan, while the non-exposed group are 17818.36 yuan, there is no significant difference between the two groups $(\mathrm{p}=0.96)$.

\section{Table 4. Relationship between neostigmine dosage and outcome indicators}




\begin{tabular}{|llll|}
\hline & $\begin{array}{l}\text { low-dose exposed } \\
\text { group (n=829) }\end{array}$ & $\begin{array}{l}\text { the high-dose exposed } \\
\text { group (n=78) }\end{array}$ & $\begin{array}{l}\text { p } \\
\text { value }\end{array}$ \\
\hline Death (occurred / not occurred) & $1 / 828$ & $0 / 78$ & 0.76 \\
\hline $\begin{array}{l}\text { The } \\
\text { lowest oxygen saturation (\%) }\end{array}$ & $98.92 \pm 3.08$ & $98.83 \pm 2.91$ & 0.81 \\
\hline $\begin{array}{l}\text { Frequency of hypoxemia (occurred / } \\
\text { not occurred) }\end{array}$ & $20 / 809$ & & 0.44 \\
\hline & & $3 / 75$ & \\
\hline Length of stay(day) & $5.67 \pm 6.21$ & & 0.83 \\
\hline & & $5.51 \pm 5.18$ & \\
\hline Hospitalization expenses (yuan) & $17957.52 \pm 20864.51$ & $17818.36 \pm 26083.66$ & 0.96 \\
\hline
\end{tabular}

Note: low dose exposed group refers to the dose of $<=0.02 \mathrm{mg} / \mathrm{kg}$; High dose exposed group refers to the dose $>0.02 \mathrm{mg} / \mathrm{kg}$.

\section{Discussion}

In this study, we did propensity score matching of 4358 cases of children and finally analyzed the data of 1820 cases of children.

In the observational study, the size of the effect, the dose-response and the control of confounding factors determine the level of research evidence. In this study, although the sample size reached 1820 cases, neostigmine did not show significant effect in all the outcome indicators. Secondly, in this study, we conducted subgroup analysis according to the dose of neostigmine, but no obvious dose effect relationship was found. Thirdly, we analyzed the confounding factors that may influence the results of the study. The analysis of confounding factors included the general situation of patients, the amounts of anesthetics used during the operation, and the length of anesthesia operation, including ASA grade, gender, age, weight, anesthesia time, operation time, intraoperative infusion volume, airway device, intraoperative blood transfusion, muscle relaxant use and opioid use. We also matched the information of the children with the propensity score according to these confounding factors, which basically eliminated the influence of the confounding factors on the results of the study. Therefore, although the internal reliability of this study is high, the evidence level of this study is not high from the level of evidence of observational research.

From the results of the study, the use of neostigmine has no relationship with whether it can reduce the mortality, improve the postoperative lowest oxygen saturation, reduce the incidence of postoperative 
hypoxemia, save medical costs and shorten the length of hospital stay. This conclusion is different from other authors' early reports. For example, a study published by Grosse-Sundrup ${ }^{[45]}$ found that the use of neostigmine increased the risk of postoperative oxygen saturation below 90 percent and increased the rate of reintubation. There may be two reasons for inconsistent results. First of all, the subjects of our study are children patients, which may be different from those of previous studies. In addition, previous studies did not conduct a separate analysis or subgroup analysis for pediatric patients. Secondly, previous studies did not consider the impact of opioids on postoperative respiratory function. Therefore, in this study, opioids were used as an important confounding factor for propensity score matching. In other studies ${ }^{[46,47]}$, it was found that the use of muscle relaxants could reduce postoperative mortality, but our findings did not. The main reason should be that the mortality rate of the subjects included in this study is not high. The majority of the children (91.43\%) included in this study were ASA grade I-II and the perioperative mortality rate was not high. A larger sample size may be needed to test the difference between the two groups. Therefore, compared with the previous literature, the biggest difference of our research is that the applicable objects are different. The results of our study are mainly applicable to pediatric surgery patients, especially ASA I-II children.

In addition, it can be seen from the results of this study that neostigmine does not produce different outcomes for children of different ages, and different doses of neostigmine do not produce different outcomes for children. Early studies have found that patients of different ages respond differently to the same dose of neostigmine ${ }^{[24,48]}$. However, we can see from our study that this difference does not change the important outcome indicators of patients. Second, early studies also pointed out that small dose of neostigmine is necessary to antagonize the residual neuromuscular blockade in pediatric patients during recovery from anesthesia ${ }^{[49]}$ and the administration of neostigmine greater than $0.02 \mathrm{mg} / \mathrm{kg}$ in pediatric patients can't bring more benefits ${ }^{[50]}$. This result is consistent with the result of our study. In addition, the required dosage of neostigmine in pediatric patients is smaller than that in adult patients, and the effect is faster ${ }^{[51]}$. And with the increase of neostigmine dosage, the recovery time did not shorten ${ }^{[52]}$. Therefore, for children patients, a small dose of neostigmine can play a sufficient antagonistic effect. With the increase of dose, the incidence of adverse reactions may increase.

Although in this study, we try our best to improve the internal reliability of this study from the perspective of methodology and statistics, there are still some limitations in this study. First of all, in order to improve the utilization rate of pediatric surgery room, nearly half of the children will be extubated in the PACU. In addition to speeding up the operation of the main reason for extubation, some of the children who had used more muscle relaxants or those who had long anesthesia had to extubate in the PACU for the sake of more stable extubation. In this part of children, the proportion of children with larger use of muscle relaxants may be higher, and the possibility of postoperative death and hypoxemia is also greater. However, it is a pity that the center has not yet installed the operation anesthesia information system in the PACU, so it is unable to obtain the data of these children. Therefore, there may be some selective bias in the inclusion of children. In addition, some of the children who left the hospital without doctor's advice may be due to the serious illness and their family members giving up treatment. However, in our data, this 
part of children with serious illness can't be reflected, which may lead to information bias in the study. Secondly, because there is no record of muscle relaxation monitoring in the operation anesthesia information system of the center, we can't determine the difference in the incidence of postoperative residual neuromuscular blockade between the two groups, so there is partial information bias in this study. But analyzing the original data, we can see that the average age of children given neostigmine is younger and the operation time is shorter. This shows that in clinical work, for short-term surgery and young children, because the possibility of postoperative residual neuromuscular blockade is greater, and the harm is more serious, clinical anesthesiologists prefer to use neostigmine to prevent the potential risk of residual neuromuscular blockade or treat the existing residual neuromuscular blockade at that time. The risk of hypoxemia is higher in children with short operation or younger age, and these children may be excluded due to the matching of propensity score, so there is no significant difference between the two groups. Thirdly, because the use of neuromuscular monitoring is not recorded in the surgical information system, we have no way to determine whether the decision to use neostigmine in patients is made under neuromuscular monitoring or whether the administration time of neostigmine is correct. In the group of children using neostigmine, there may be three ways of administration: using neostigmine according to muscle relaxation monitoring results, using neostigmine according to clinical experience and using neostigmine routinely. Studies have shown that in adult patients, when the TOF count is less than 2 , neostigmine should not be considered to antagonize the residual neuromuscular blockade. If the TOF count is $2-4$, or the TOF ratio is less than 0.4 , the use of $0.05 \mathrm{mg} / \mathrm{kg}-0.07 \mathrm{mg} / \mathrm{kg}$ of neostigmine should be considered. If the TOF count is equal to 4 , or the TOF ratio is between 0.4 and $0.9,0.02 \mathrm{mg} / \mathrm{kg}-0.03 \mathrm{mg} / \mathrm{kg}$ of neostigmine should be considered. If TOF ratio is greater than 0.9 , it is not necessary to use neostigmine after operation ${ }^{[53-55]}$. It can be inferred that the clinical effect of drug administration at different time may be different, especially when anesthesiologists give drugs according to their own clinical experience, the uncertainty will be greatly increased. Therefore, in the use of neostigmine in children, the heterogeneity within the group may lead to the reduction of the difference between the two groups of children in this study, resulting in no statistically significant difference. However, due to the lack of heterogeneity information, we can't make further analysis. Fourth, due to the defect of retrospective study, we did not get the index of early recovery such as extubation time and outpatient time. And we did not get the index data of the outdoor operation about whether the child developed apnea and hypoxemia in PACU and ward.

In conclusion, the use of neostigmine in the recovery period of general anesthesia does not change the mortality, the lowest oxygen saturation, the incidence of postoperative hypoxemia, the medical cost and the length of hospital stay. However, due to the limitations of this retrospective study and some confounding factors in the study can't be eliminated, the results of this study need to be further confirmed by future prospective studies.

\section{Declarations}

Acknowledgments 
The authors appreciate the patient's consent to this case report.

\section{Funding}

This report was supported by National Key RESEARCH and Development Program (2020YFC2005303).

\section{Availability of data and materials}

The datasets supporting the conclusions of this article are included within the article.

\section{Authors' contributions}

Dr. Hongyang Chen and Dr. Lei Yang performed the anesthesia of the operation and they collected the medical records of the patient; Zining Wang and Dr. Di Yang took responsibility for investigation and data curation;. Dr. Hongyang Chen and Dr. Weiyi Zhang drafted and revised the manuscript

All authors read and approved the final manuscript.

\section{Competing interests}

The authors declare that they have no competing interests.

\section{Ethics Accordance}

All methods were implemented in accordance with relevant guidelines and regulations, and passed ethical approval and trial registration.

This study was approved by the ethics committee of West China Hospital of Sichuan University (Grant No.2019(874)). It registered in China clinical trial registration network before the implementation of the study, the registration number is ChiCTR1900028048.

\section{Informed Consent}

All the children's parents in this article have signed an informed consent form for anesthesia. Because this study is a retrospective cohort study, all data are collected through our surgical anesthesia information system after the children are discharged from the hospital『so the need for consent is deemed unnecessary.

\section{References}

1. MERETOJA O A. Neuromuscular block and current treatment strategies for its reversal in children[J]. Paediatr Anaesth, 2010, 20(7):591-604.

2. BAILLARD C, GEHAN G, REBOUL-MARTY J, et al. Residual curarization in the recovery room after vecuronium[J]. Br J Anaesth, 2000, 84(3):394-5. 
3. DEBAENE B, PLAUD B, DILLY M P, et al. Residual paralysis in the PACU after a single intubating dose of nondepolarizing muscle relaxant with an intermediate duration of action[J]. Anesthesiology, 2003, 98(5):1042-8.

4. HUNTER J M. Reversal of residual neuromuscular block: complications associated with perioperative management of muscle relaxation[J]. Br J Anaesth, 2017, 119(suppl_1):i53-i62.

5. MURPHY G S, SZOKOL J W, AVRAM M J, et al. Neostigmine Administration after Spontaneous Recovery to a Train-of-Four Ratio of 0.9 to 1.0: A Randomized Controlled Trial of the Effect on Neuromuscular and Clinical Recovery[J]. Anesthesiology, 2018, 128(1):27-37.

6. MURPHY G S, BRULL S J. Residual neuromuscular block: lessons unlearned. Part I: definitions, incidence, and adverse physiologic effects of residual neuromuscular block[J]. Anesth Analg, 2010, 111(1):120-8.

7. KLUCKA J, KOSINOVA M, KRIKAVA I, et al. Residual neuromuscular block in paediatric anaesthesia[J]. Br J Anaesth, 2019, 122(1):e1-e2.

8. TODD M M, HINDMAN B J, KING B J. The implementation of quantitative electromyographic neuromuscular monitoring in an academic anesthesia department[J]. Anesth Analg, 2014, 119(2):323-31.

9. CHECKETTS M R, ALLADI R, FERGUSON K, et al. Recommendations for standards of monitoring during anaesthesia and recovery 2015: Association of Anaesthetists of Great Britain and Ireland[J]. Anaesthesia, 2016, 71(1):85-93.

10. NAGUIB M, BRULL S J, KOPMAN A F, et al. Consensus Statement on Perioperative Use of Neuromuscular Monitoring[J]. Anesthesia and Analgesia, 2018, 127(1):71-80.

11. NAGUIB M, KOPMAN A F, LIEN C A, et al. A Survey of Current Management of Neuromuscular Block in the United States and Europe[J]. Anesthesia and Analgesia, 2010, 111(1):110-119.

12. FUCHS-BUDER T, MEISTELMAN C. [Monitoring of neuromuscular block and prevention of residual paralysis][J]. Ann Fr Anesth Reanim, 2009, 28 Suppl 2:S46-50.

13. SODERSTROM C M, ESKILDSEN K Z, GATKE M R, et al. Objective neuromuscular monitoring of neuromuscular blockade in Denmark: an online-based survey of current practice[J]. Acta Anaesthesiol Scand, 2017, 61(6):619-626.

14. PHILLIPS S, STEWART P A, BILGIN A B. A survey of the management of neuromuscular blockade monitoring in Australia and New Zealand[J]. Anaesth Intensive Care, 2013, 41(3):374-9.

15. BATISTAKI C, VAGDATLI K, TSIOTOU A, et al. A multicenter survey on the use of neuromuscular blockade in Greece. Does the real-world clinical practice indicate the necessity of guidelines?[J]. Journal of Anaesthesiology Clinical Pharmacology, 2019, 35(2):202-214.

16. GRAYLING M, SWEENEY B P. Recovery from neuromuscular blockade: a survey of practice[J]. Anaesthesia, 2007, 62(8):806-9.

17. NAVA-OCAMPO A A, RAMIREZ-MORA J C, MOYAO-GARCIA D, et al. Preferences of Mexican anesthesiologists for vecuronium, rocuronium, or other neuromuscular blocking agents: a survey[J]. BMC Anesthesiol, 2002, 2(1):2. 
18. DI MARCO P, DELLA ROCCA G, IANNUCCELLI F, et al. Knowledge of residual curarization: an Italian survey[J]. Acta Anaesthesiol Scand, 2010, 54(3):307-12.

19. VIBY-MOGENSEN J, CLAUDIUS C. Evidence-based management of neuromuscular block[J]. Anesth Analg, 2010, 111(1):1-2.

20. MILLER R D, WARD T A. Monitoring and pharmacologic reversal of a nondepolarizing neuromuscular blockade should be routine[J]. Anesth Analg, 2010, 111(1):3-5.

21. BAILLARD C, CLEC'H C, CATINEAU J, et al. Postoperative residual neuromuscular block: a survey of management[J]. Br J Anaesth, 2005, 95(5):622-6.

22. RD.MILLER. Philadephia:Elsevier Churchill Livingstone[J]. Miller's Anesthesia. 7th ed., 2009.

23. FISHER D M, CRONNELLY R, MILLER R D, et al. The neuromuscular pharmacology of neostigmine in infants and children[J]. Anesthesiology, 1983, 59(3):220-5.

24. KIRKEGAARD-NIELSEN H, MERETOJA O A, WIRTAVUORI K. Reversal of atracurium-induced neuromuscular block in paediatric patients[J]. Acta Anaesthesiol Scand, 1995, 39(7):906-11.

25. CALDWELL J E. Reversal of residual neuromuscular block with neostigmine at one to four hours after a single intubating dose of vecuronium[J]. Anesth Analg, 1995, 80(6):1168-74.

26. WATCHA M F, SAFAVI F Z, MCCULLOCH D A, et al. Effect of antagonism of mivacurium-induced neuromuscular block on postoperative emesis in children[J]. Anesth Analg, 1995, 80(4):713-7.

27. HUNTER J M, FLOCKTON E A. The doughnut and the hole: a new pharmacological concept for anaesthetists[J]. Br J Anaesth, 2006, 97(2):123-6.

28. SAOKHAM P, MUANKAEW C, JANSOOK P, et al. Solubility of Cyclodextrins and Drug/Cyclodextrin Complexes[J]. Molecules, 2018, 23(5).

29. CHANDRASEKHAR K, TOGIOKA B M, JEFFERS J L. Sugammadex [M]. StatPearls. Treasure Island (FL). 2021.

30. HONING G, MARTINI C H, BOM A, et al. Safety of sugammadex for reversal of neuromuscular block[J]. Expert Opin Drug Saf, 2019, 18(10):883-891.

31. CHAMBERS D, PAULDEN M, PATON F, et al. Sugammadex for reversal of neuromuscular block after rapid sequence intubation: a systematic review and economic assessment[J]. Br J Anaesth, 2010, 105(5):568-75.

32. ADAM J M, BENNETT D J, BOM A, et al. Cyclodextrin-derived host molecules as reversal agents for the neuromuscular blocker rocuronium bromide: synthesis and structure-activity relationships[J]. J Med Chem, 2002, 45(9):1806-16.

33. MIYAZAKI Y, SUNAGA H, KIDA K, et al. Incidence of Anaphylaxis Associated With Sugammadex[J]. Anesth Analg, 2018, 126(5):1505-1508.

34. TADOKORO F, MORITA K, MICHIHATA N, et al. Association between sugammadex and anaphylaxis in pediatric patients: A nested case-control study using a national inpatient database[J]. Paediatr Anaesth, 2018, 28(7):654-659. 
35. MCDONNELL N J, PAVY T J, GREEN L K, et al. Sugammadex in the management of rocuroniuminduced anaphylaxis[J]. Br J Anaesth, 2011, 106(2):199-201.

36. KAWANO T, TAMURA T, HAMAGUCHI M, et al. Successful management of rocuronium-induced anaphylactic reactions with sugammadex: a case report[J]. J Clin Anesth, 2012, 24(1):62-4.

37. BINCZAK M, FISCHLER M, LE GUEN M. Efficacy of Sugammadex in Preventing Skin Test Reaction in a Patient With Confirmed Rocuronium Anaphylaxis: A Case Report[J]. A A Pract, 2019, 13(1):17-19.

38. TAKAZAWA T, MITSUHATA H, MERTES P M. Sugammadex and rocuronium-induced anaphylaxis[J]. J Anesth, 2016, 30(2):290-7.

39. PLAUD B, MERETOJA O, HOFMOCKEL R, et al. Reversal of rocuronium-induced neuromuscular blockade with sugammadex in pediatric and adult surgical patients[J]. Anesthesiology, 2009, 110(2):284-94.

40. OZMETE O, BALI C, ERGENOGLU P, et al. Anesthesia management and sugammadex experience in a neonate for Galen vein aneurysm[J]. J Clin Anesth, 2016, 31:36-7.

41. LANGLEY R J, MCFADZEAN J, MCCORMACK J. The presumed central nervous system effects of rocuronium in a neonate and its reversal with sugammadex[J]. Paediatr Anaesth, 2016, 26(1):10911.

42. BEVAN D R, DONATI F, KOPMAN A F. Reversal of neuromuscular blockade[J]. Anesthesiology, 1992, 77(4):785-805.

43. HERBSTREIT F, ZIGRAHN D, OCHTERBECK C, et al. Neostigmine/glycopyrrolate administered after recovery from neuromuscular block increases upper airway collapsibility by decreasing genioglossus muscle activity in response to negative pharyngeal pressure[J]. Anesthesiology, 2010, 113(6):12808.

44. MCLEAN D J, DIAZ-GIL D, FARHAN H N, et al. Dose-dependent Association between Intermediateacting Neuromuscular-blocking Agents and Postoperative Respiratory Complications[J]. Anesthesiology, 2015, 122(6):1201-13.

45. GROSSE-SUNDRUP M, HENNEMAN J P, SANDBERG W S, et al. Intermediate acting non-depolarizing neuromuscular blocking agents and risk of postoperative respiratory complications: prospective propensity score matched cohort study[J]. Bmj-British Medical Journal, 2012, 345.

46. BRONSERT M R, HENDERSON W G, MONK T G, et al. Intermediate-Acting Nondepolarizing Neuromuscular Blocking Agents and Risk of Postoperative 30-Day Morbidity and Mortality, and Long-term Survival[J]. Anesthesia and Analgesia, 2017, 124(5):1476-1483.

47. BILEN-ROSAS G, KARANIKOLAS M, EVERS A, et al. Impact of anesthesia management characteristics on severe morbidity and mortality: are we convinced?[J]. Anesthesiology, 2006, 104(1):204; author reply 205-6.

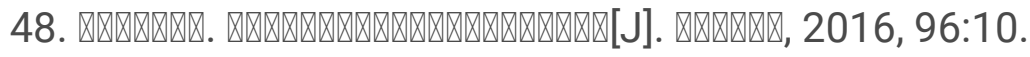

49. HUNTER J M. Is it always necessary to antagonize residual neuromuscular block? Do children differ from adults?[J]. Br J Anaesth, 1996, 77(6):707-9. 
50. ABDULATIF M, MOWAFI H, AL-GHAMDI A, et al. Dose-response relationships for neostigmine antagonism of rocuronium-induced neuromuscular block in children and adults[J]. $\mathrm{Br} \mathrm{J}$ Anaesth, 1996, 77(6):710-5.

51. BEVAN J C, PURDAY J P, REIMER E J, et al. Reversal of doxacurium and pancuronium neuromuscular blockade with neostigmine in children[J]. Can J Anaesth, 1994, 41(11):1074-80.

52. GWINNUTT C L, WALKER R W, MEAKIN G. Antagonism of intense atracurium-induced neuromuscular block in children[J]. Br J Anaesth, 1991, 67(1):13-6.

53. LUO J, CHEN S, MIN S, et al. Reevaluation and update on efficacy and safety of neostigmine for reversal of neuromuscular blockade[J]. Ther Clin Risk Manag, 2018, 14:2397-2406.

54. BRULL S J, KOPMAN A F. Current Status of Neuromuscular Reversal and Monitoring: Challenges and Opportunities[J]. Anesthesiology, 2017, 126(1):173-190.

55. KOPMAN A F, EIKERMANN M. Antagonism of non-depolarising neuromuscular block: current practice[J]. Anaesthesia, 2009, 64 Suppl 1:22-30.

\section{Figures}

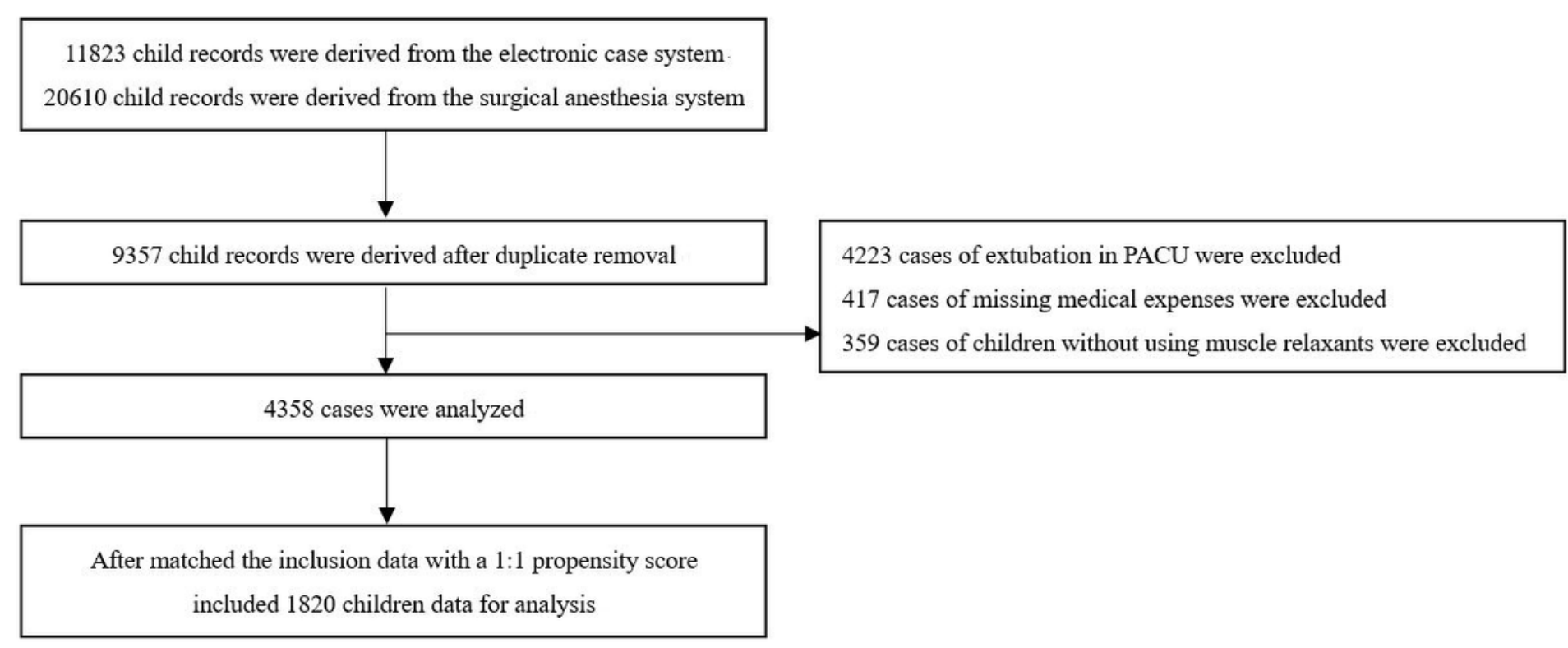

\section{Figure 1}

Flow chart of inclusion of children 